\title{
Towards Programs Sustainability: An Empirical Analysis of the Socio-Cultural Determinants for Effective Community Participation in Development Programs in Tanzania
}

\author{
Daniel Wandera Clief Naku ${ }^{1 *} \quad$ Dr. Jacob Kihila ${ }^{2} \quad$ Prof. Eleuther A Mwageni ${ }^{3}$ \\ 1.PhD Researcher, Institute of Human Settlements Studies, Ardhi University- Tanzania- East Africa \\ 2.Senior Research Fellow, Institute of Human Settlements Studies, Ardhi University- Tanzania- East Africa \\ 3.Senior Lecturer, School of Spatial Planning and Social Sciences, Ardhi University- Tanzania- East Africa
}

\begin{abstract}
The link between participation and development programs is embedded in the concept of participatory development. As such, there is no doubt that community participation has indeed been a constant theme in development dialogues for the past 50 years. This shows how important the concept of community participation continues to stand out as one of those key catalysts for successful implementation of development programs such that they remain sustainable. On account of this perception, this paper therefore set out to explore socio-cultural determinants for effective community participation in development programs in the context of Tanzania. Precisely, the paper posits that in order to achieve program sustainability, effective community participation in such programs is of paramount importance. Hence the need to ensure that any factors that have the potential to influence the extent of peoples' participation in development programs need to be well responded to and addressed. In light of this view, this paper therefore looked into the socio-cultural factors or determinants so as to establish what could be the key socio-cultural factors for influencing effective community participation in development programs.
\end{abstract}

Keywords: Sustainability, Development Programs, Program Sustainability, Community Participation, Sociocultural determinants

DOI: $10.7176 / \mathrm{JESD} / 12-18-03$

Publication date:September $30^{\text {th }} 2021$

\section{INTRODUCTION:}

The need for effective community participation as one of the means for enhancing programs sustainability is increasingly becoming a pre-requisite for successful implementation of development programs in Tanzania and worldwide. Bamber et al (2010), stresses that development programs at the community level are normally designed and implemented with the intentions of achieving the desired objective of enhancing community development and that they remain sustainable.

Sebastian et al (2018) further stress that when a program is not sustainable; its impacts decrease leading to unmet expectations and thus affecting development efforts of the community as a whole. In order to avoid this situation, Wasilwa (2015) suggests that active participation which is open and allows community members to actively take part in all stages of the program is essential for the sustainability of a program.

According to Wasilwa (2015), it leads to capacity building, which enables the community to be more effective and efficient in the process of identifying, monitoring and evaluating the program and thus contributing to its sustainability. In addition, Akumu and Onono (2017) also echo that community participation allows beneficiaries to influence the direction and execution of development programs rather than merely receive a share of the program. Similarly, according to the 2013 Human Development Report (UNDP, 2013), in order to walk in the human development pathway, people should engage fully in activities that reform the lives and they should be able to participate in policy making process and results.

Generally, effective community participation is today seen as one of the means for enhancing programs sustainability and is increasingly becoming a pre-requisite for successful implementation of development programs. Unfortunately, in the context of Tanzania, this study found that there was inadequate empirical research on the socio-cultural determinants for enhancing effective community participation in development programs sustainability and thus a knowledge gap which in the interest of this paper, it is necessary to be addressed.

\section{LITERATURE}

Community participation is fundamental to achieving sustainable community development in any community as pointed out by Beck and Crawley (2002). In addition, Schutte (2016) further stresses that the participation of the community in development programs that seek to bring about sustainable development in such a community is very essential. In fact, according to Odoyo (2013), effective community participation in development projects and programs need to be fully embraced if sustainable development is to be attained in communities. Odoyo 
(2013) further emphasizes that, in order to achieve effective community participation in development programs, there is a need to pay close attention to key factors that serve as determinants and thus ensure that such factors are supportive to the process of community participation in development projects and programs.

In support of this view, Apsalone and Sumilo (2015) socio-cultural factors are among the most influencing determinants to peoples' effective participation in development programs and projects. According to the authors (Apsalone and Sumilo,2015), socio-cultural related determinants largely constitute a combination of social and cultural factors. These factors tend to influence the manner in which people get involved in development initiatives such as programs and projects on different scales.

Hence, taking care of them during the program design stage is very important because this will ensure that the extent of peoples' participation in a particular program is not compromised by such factors. These factors range from factors such as shared values, norms, peoples' attitude, skills/capacity, beliefs, awareness, gender to ethnicity.

Apsalone and Sumilo (2015) further stresses that these factors are very significant and have the potential to either positively or negatively influence peoples' participation in any development program. In line with these views, theory does again inform us that socio-cultural factors such as shared values, norms, peoples' attitude, skills/capacity, beliefs, awareness, gender and ethnicity are very determining factors when it comes to influencing the participation of people in development programs. Hence, from the theoretical point of view, these factors need to be taken into consideration to guarantee effective participation of community members in any development program.

Findings from other studies in relation to this subject matter also revealed that socio- cultural factors have a greater role to play in influencing people's participation in development programs. For instance, Sibanda (2011) did a study on the role of community participation in development initiatives: the case of the Danga ecological sanitation project in the Zvishavane district, Zimbabwe. The study used both qualitative and quantitative data and the results of the study showed that community participation was very low in the ecological sanitation project due to lack of commitment by the project implementers to fully involve community members. As a result, the project had a poor performance record hence lack of sustainability.

In a study conducted in Bangladesh, Mohammed (2010), found that participation of local communities in development projects especially in the planning aspect was very low (7\%) while the percentage is a bit high (24) in the implementation stage though it is mainly managed, guided and directed by patron-client relations, mutual benefit-sharing and personal relations. Participation is limited to the rich and socially influential persons, without whom the elected representatives cannot think of their political successes.

Similarly, Nkonjera (2008) did a study on community participation in development projects that had interest in water supply in Mbeya District, Tanzania. The study used descriptive statistic with a sample size population of 120. The study found that the level of participation in selected rural water development projects undertaken was low and this was attributed to poor individual attitudes, beliefs of people and leadership related problems.

Generally, from the above literature, it can be summed up that the influence of socio-cultural determinants cannot be underestimated in influencing the participation of community members in development.

\section{STUDY CONCEPTUAL FRAMEWORK}

On account of the reviewed literature, socio-cultural determinants such as attitude, beliefs, awareness, culture, skills, commitment and capacity were identified as possible influencing factors to participation of community members in development programs. Figure 1 below conceptually sums up these factors and how they are linked to effective community participation and the sustainability of development programs. 


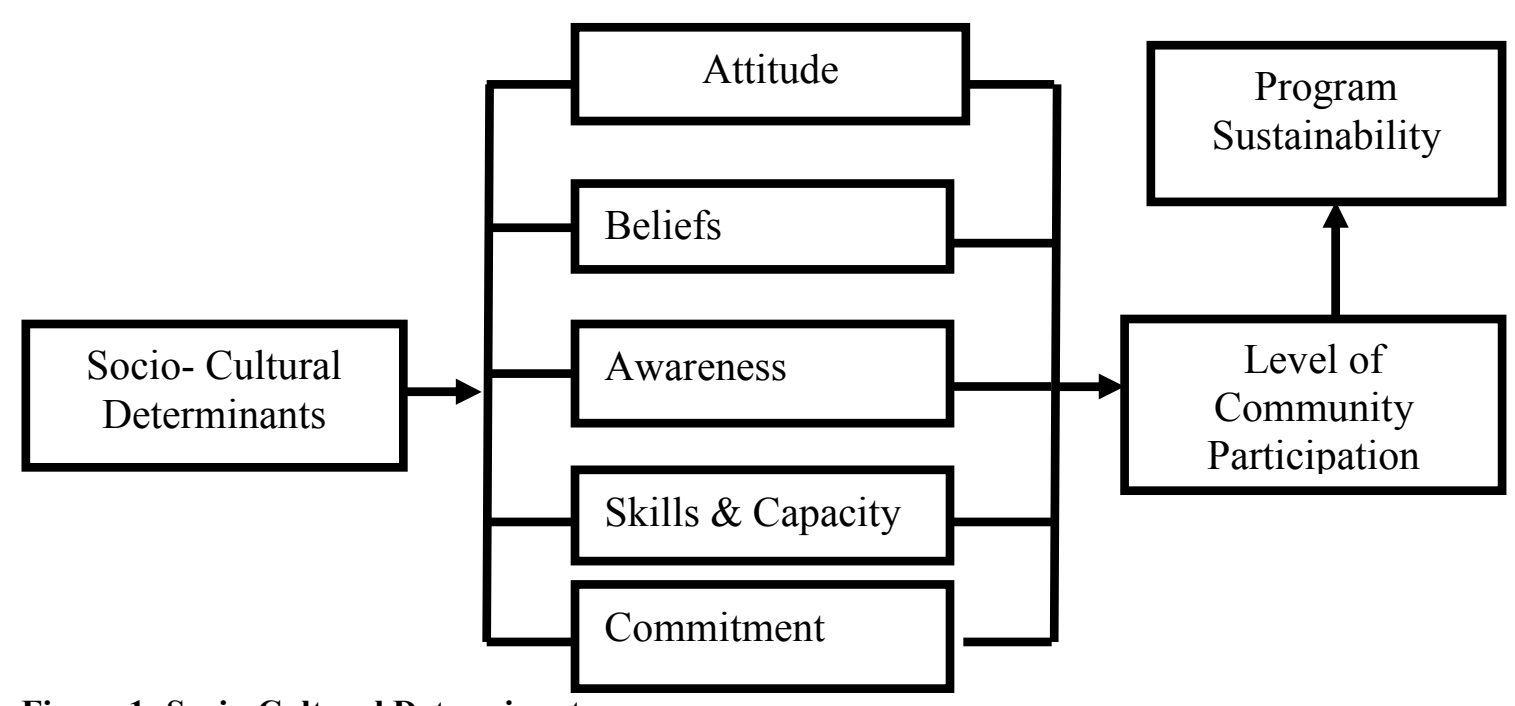

Figure 1: Socio-Cultural Determinants

\section{METHODOLOGY:}

The study employed a cross - sectional research design and a case study research strategy. The cross-sectional research esign was used because it is best suited for studies that aim at finding out the prevalence of a phenomenon, situation, problem, attitude or issue, by taking a cross-section of the population. In addition, Kumar (2011) stress that cross sectional designs are useful in obtaining an overall 'picture' as it stands at the time of the study and designed to study some phenomenon by taking a cross-section of it at one time. As such, this design was chosen in line with the above stated views whereby the researcher was interested in examining socio-economic determinants of effective community participation in development programs.

On the other hand, the case study research strategy was used because it is open to use of other approaches of analysis including both qualitative and quantitative approaches that the study intended to use. Yin (2003) observed that case study research strategy can accommodate both qualitative and quantitative approaches, thus allowing the researcher to get a rich mix of data for the study.

Sampling procedures included purposive sampling for key informants and random sampling for programme beneficiaries. Using a 95\% confidence level and Yamane 1967 formula for sample size determination, a sample of 316 program beneficiaries from three study areas of Arusha, Morogoro and Iringa within Tanzania were involved in the study. This sample size was drawn from four examined program categories that included the locally fully funded program, government fully funded program, and donor fully funded program as well as the joint fully funded program.

Findings of the study were analysed based on two analysis approaches that included the within case analysis and comparative case analysis. The within case analysis which is an analytical approach in which each single case in the study is examined independently and in detail while the comparative case analysis is an analytical approach used to compare findings from different single analysed cases. In the case of this study, four development programs were first analysed independently and later the findings from each case were compared.

\section{RESULTS AND DISCUSSION ON SOCIO-CULTURAL DETERMINANTS FOR EFFECTIVE COMMUNITY PARTICIPATION IN DEVELOPMENT PROGRAMS IN TANZANIA}

\subsection{RESULTS AND DISCUSSIONS BASED ON THE WITHIN CASE ANALYSIS}

\subsubsection{Within Analysis for the Locally Fully Funded Development Programs}

As pointed out by Apsalone and Sumilo (2015), socio-cultural factors are among the determining factors for effective community participation in development programs. In the case of the examined locally fully funded development program in this study, six socio-cultural factors were revealed by study respondents as influential factors in their participation in the program and they include attitude, values, skills and capacity, beliefs, awareness and gender. Out of the six factors, three factors that include attitude, beliefs and awareness were identified as the most influential factors.

These three factors according to the respondents were very critical in determining the participation of people in the program because of the voluntary nature of the program. As such, for someone to effectively participate in the program, he or she needed to have a positive attitude towards the program, belief in the program and awareness of the relevance of the program to him or her as an individual. An interviewed respondent stated that:

'As an individual, it was not about what tangible thing I was to get from the program but I only needed to have 
the right attitude to like the program and join it'

Generally, from the obtained responses, twenty-eight-point four percent $(28.4 \%)$ indicated that attitude was very influential, twenty-seven-point three percent (27.3\%) stressed belief while twenty seven percent $(27 \%)$ indicated awareness. These findings largely concur with findings from a study by Said (2016) who found that issues of community attitude, self-belief and awareness were indeed key for successful implementation of community education programs.

These findings were not different from the views of the Executive Director and the Program Coordinator as key informants in the study. In fact, according to them, attitude was the most paramount factor for anyone who was ready to join the program. The Executive Director stressed that:

'At the start, this program attracted so many youths when it was first launched but as time went by, we have seen the number reducing which boils down to the attitude of the individual. If you have no positive attitude, you cannot manage to be part of a voluntary program of this nature. All other factors were secondary in my view'

On the contrary, results from Focus Group Discussions showed that participants still maintained the perception that all the three factors, that is, attitude, belief and awareness were all very important determinants in the participation of individuals in the program. For instance, one of the participants in the Focus Group Discussion pointed out that:

'Personally, attitude or belief might be important but if I am not aware of how beneficial the program will be to me, then I still may not participate but also if I know how beneficial the program is but I have a negative attitude either with the program itself or the implementers of the program, again I may not be encouraged to participate. I think it is very important that the three aspects be seen as equal in terms of importance. On the contrary, being a man or woman does not matter to any of us here. You simply need to participate if you have the right attitude, belief and awareness.'

On account of the above findings, it was evident that in the case of the examined locally fully funded development program, the three socio-cultural factors i.e., attitude, beliefs and awareness were key in influencing participation of the youths in the program. This implied that from what Apsalone and Sumilo (2015) pointed out as socio- cultural determinants, the above three mentioned factors were the most dominant in the explored program while factors such as values, gender as well as skills and capacity had limited influence. Figure 2 presents a summary of these findings.

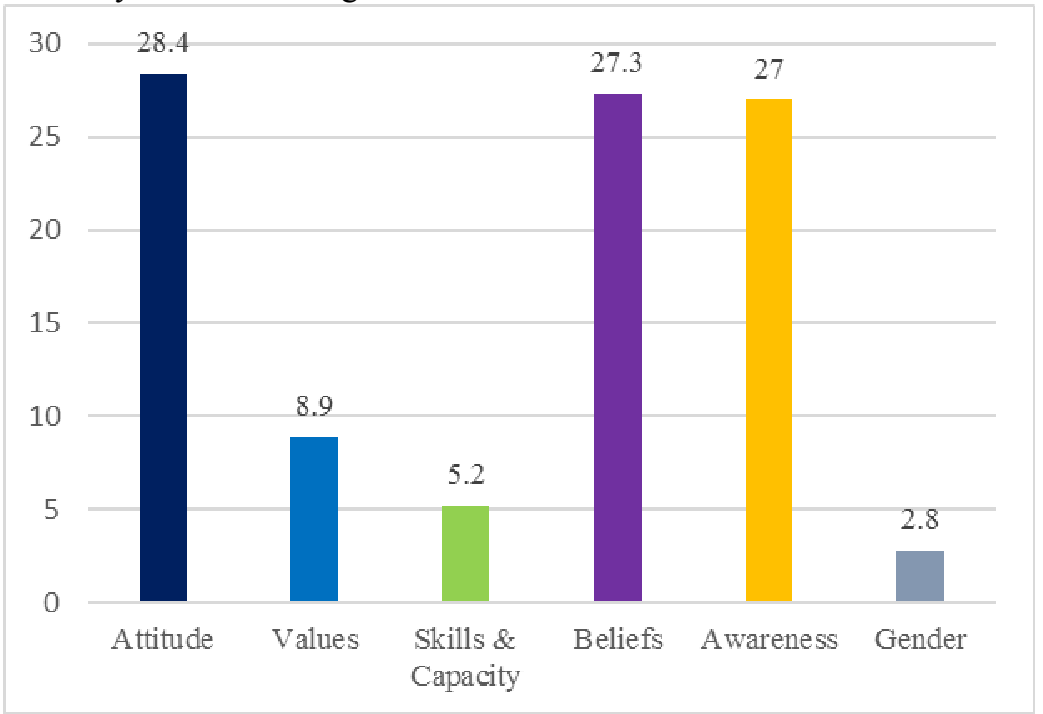

Figure 2: Socio - Cultural Determinants in Locally Fully Funded Development Programs Source: Field Survey, 2020

\subsubsection{Within Analysis for the Government Fully Funded Development Programs}

Concerning the socio-cultural determinants for effective community participation in development programs, findings revealed that in the case of the examined government fully funded development program, factors such as Awareness, Attitude, Beliefs and others such as being confident and focused played an influential role in determining people's participation in such programs.

According to respondents, sixty-four-point three percent $(64.3 \%)$ of them revealed that awareness was the main driving factor influencing their participation in the program. In the views of the interviewed respondents, participation in government programs requires one to be aware of what he or she is participating in because of the consequences that may come with it when things go wrong.

These findings on the need for awareness as a determining factor for people's participation in programs concur with the findings of Agosti et. al., (2019). The authors in their study about the importance of awareness, 
support and inner strength to balance everyday life" in Sweden pointed out that awareness was such an important factor in any program.

The implication of such finding in relation to the subject matter of inquiry in this study is that, in order to have effective community participation that will lead to program sustainability, it is very important that the intended program beneficiaries are made aware of what the program is about. One of the interviewed respondents commented that:

'Government programs are not like donor programs or programs that people in a community start on their own. With government programs, there are serious consequences that one may face if things go wrong and for that matter, you need to be aware of the program and how you participate in it.'

On the other hand, fourteen-point three percent $(14.3 \%)$ of the respondents identified attitude, fourteenpoint three percent $(14.3 \%)$ stated beliefs while seven-point one percent $(7.1 \%)$ felt that other factors such as being confident and focused were very crucial factors in influencing an individual to participate in government development programs of this nature.

However, discussion with the Officer in Charge of Statistics, Monitoring and Evaluation of programs in secondary schools within Arusha City as a key informant revealed that besides the above factors, somebody's technical abilities in terms of skills was equally important. According to the key informant, a government fully funded development program like the EP4R assumes that head teachers have technical abilities to manage the program.

Hence, on the basis of the findings concerning the examined government fully funded development program, this study found that besides the several factors that authors such as Apsalone and Sumilo (2015) appear to point out as socio-cultural determinants of effective community participation in development programs, awareness was the most crucial factor in the context of this program.

The findings on socio-cultural determinants also appear to point to the fact that, a development program of this nature may not necessarily be affected by a single determining factor, rather, a combination of factors but in varying degrees of influence. Figure 3 presents the results of this analysis.

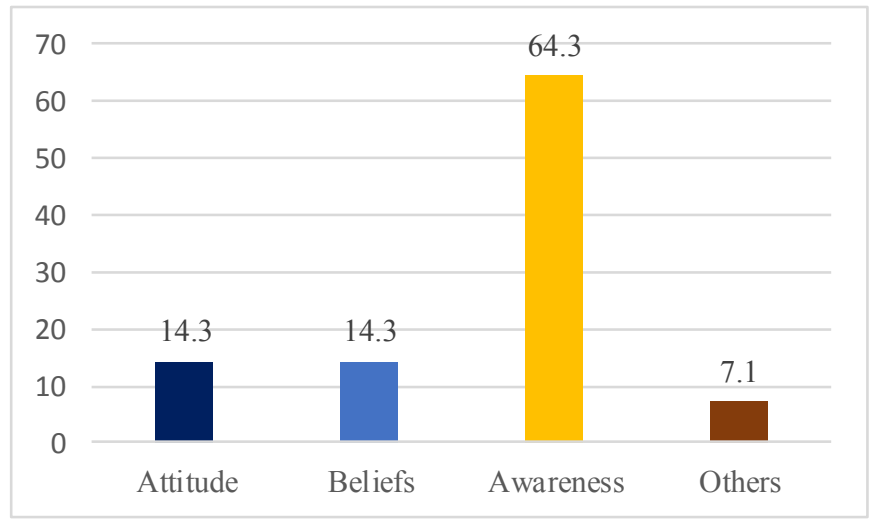

Figure 3: Socio-cultural Determinants in Government Fully Funded Development Programs

Source: Field Survey, 2020

\subsubsection{Within Analysis for the Donor Fully Funded Development Programs}

Findings on the socio-cultural determinants for effective community participation in the examined donor fully funded development program revealed that four factors that included attitude, beliefs, skills/capacity and awareness were considered as determining factors for people's participation in the investigated donor fully funded development program.

However, of the four mentioned factors, sixty-point nine percent $60.9 \%$ of the respondents pointed out that attitude was the most influential factor for peoples' participation in the examined program. This finding is similar to the views of Said (2016) who also found that community attitude plays a big role in influencing the extent of community members' participation in a particular program. As such, the implication of such finding is that, from the socio-cultural point of view, the issue of attitude is very important in determining the extent of participation in donor fully funded programs.

According to the respondents, expected returns from the program were not in the short or medium term, rather in the long term which implied that whoever had joined the program needed to tune his or her mind set to such fact. As a result, it all came down to one's attitude in terms of joining a program whose returns were said to be in the long run. Some of the interviewed persons stressed that:

'The program is profitable but this requires one to be patient, wait for trees to grow and then be able to sell at good price. In this case, one's attitude towards waiting for such a long period matters a lot in deciding on whether to participate or not participate. People had to weigh between allocating 2 acres of land that you would 
have used to cultivate food or cash crops for sell and probably get some money in a short time to take care of your family needs or cultivate trees that you will have to wait for a period not less than 10 years'

Interview with the Program Coordinator revealed that convincing people to allocate 2 acres of land to tree farming was indeed a challenging step for the success of the program. However, after constant sensitization which also involved allowing at least two people in the same location to merge their land and come up with 2 acres' people were now able to join the program. The Program Coordinator stressed that:

'I think this was the most difficult step in the success of this program. We cannot claim that we have fully succeeded because up to now, the most vulnerable people such as women that we wanted to see joining the program have not been able to join the program in good numbers. In fact, we are working on mechanisms to see how we can assist such people. Otherwise, had we failed in this area then, I am very sure the program would have also failed because no participants would have joined.'

Similarly, participants from the Focus Group Discussion shared a similar view of attitude of the individuals being an important determining factor in effectively participating in the investigated donor fully funded development program. Indeed, according to the members,

'Our lives mainly depend on land and that is where we get food to feed our children. Allocating 2 cares to tree farming was really a big challenge for us. Thanks to the program implementers who also felt our concern and agreed that we can team up with one acre each to make 2 acres and join the program'

The second noted influential factor in determining the participation of the intended program beneficiaries in the investigated donor fully funded development program was the awareness factor. This finding concurs with the findings of Lilja (2017) and Agosti et. al., (2019) who also in their studies revealed that peoples' awareness about the project or program was important to enable them decide on whether to participate or not. This therefore implies that, in the context of the examined donor fully funded program, ensuring that people are aware of what the program is about is of paramount importance.

According to the findings, $32.2 \%$ of the respondents cited awareness as being an influential factor in the participation of community members in the program. The interviewed respondents revealed that being aware of what program was about and the expected outcomes was important to them. In fact, some of the interviewed respondents in quotes stated that...;

'We are that grateful the FDT was very transparent with us concerning this program from the very start. They provided us with a lot of information which helped us to make decisions'

Finally, four-point six percent $(4.6 \%)$ of the respondents cited skills/capacity which was equated to prior knowledge as also having been influential in their participation in the program while the other $2.3 \%$ of the respondents also identified beliefs which was linked to believing in what the program implementers had told them. Figure 4 presents the findings of this analysis.

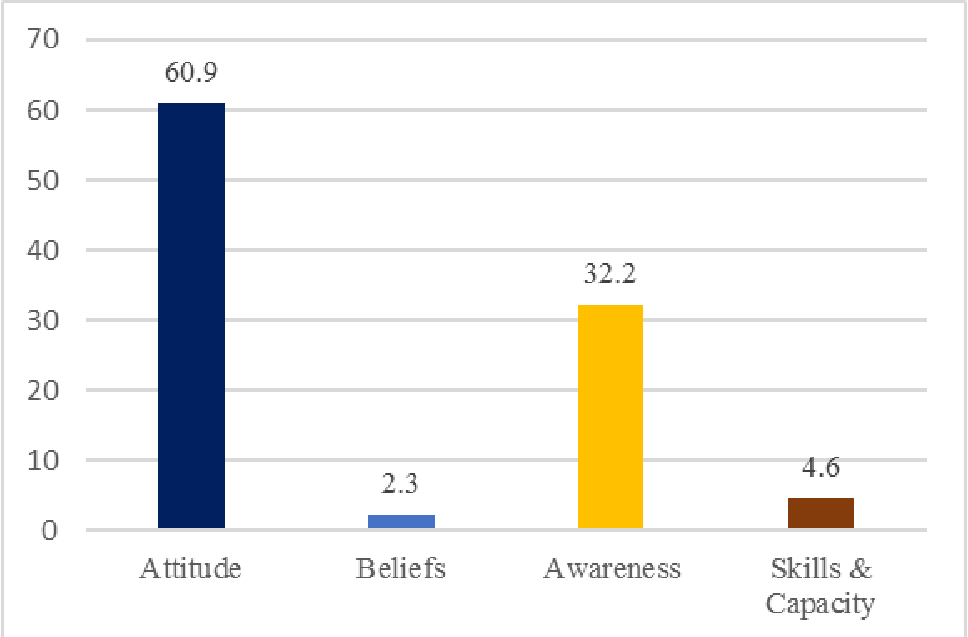

Figure 4: Socio-cultural Determinants in Donor Fully Funded Development Programs

Source: Field Survey, 2020

On account of the findings on the socio-cultural determinants for effective community participation in the studied donor fully funded development program, the study found that results appeared to affirm the views expressed by authors such as Apsalone and Sumilo (2015), Said (2016), Lilja (2017) and Agosti et. al., (2019). According to the authors, socio-cultural determinants that constitute a combination of social and cultural factors have the potential to influence the extent of peoples' involvement in any development initiatives such as programs or projects.

In addition, the study further revealed that even in the donor fully funded development programs, it is possible to have more than one socio-cultural determinant operating in a single program to influence effective 
community participation. The only difference will, however, be that some factors will have more influencing role than others as it was observed from the views of the respondents in this study.

\subsubsection{Within Analysis for the Joint Fully Funded Development Programs}

The socio-cultural determinants for effective community participation in the examined joint funded development program revealed that there were three key factors that program participants felt had greatly influenced their participation in the program. These factors include awareness, beliefs and attitude.

In the case of awareness, forty-six-point four percent (46.4\%) of the respondents indicated that this was the most determining factor from the socio-cultural point of view that had influenced people to join the program. This finding concurs with the views of Apsalone and Sumilo (2015) and Said (2016) who also noted the importance of awareness on the part of the program participants in any development project or program. This implies that the factor of awareness in the joint funded program is important in ensuring that people find reason to participate in the program and thus contribute to its sustainability.

According to the respondents, people already knew that this was a program brought into their community by the government and for that matter what remained was for people to get more informed about the program so that they could judge whether to join or not. Hence, the more they were informed and sensitized, the more they became aware of the program and joined it. One of the interviewed pointed out that:

'I joined the program very late but this is not because I didn't like the program. Rather, I needed to be well informed so that I could make the right decision. It was about me being completely aware of what the program was about and how it would assist me'

Similarly, discussion with the Program Director revealed the same understanding whereby according to the Director, the program put a lot of effort in making people understand what the program was about so that if they decided to join, they would be committed participants. The Program Director explained that:

'It was very important for us to educate people about the program so that we get the right people join the program. This is a program whose benefits are not coming tomorrow but will come after 7 to 10 years. Getting people aware of these facts was very crucial to us.'

In the same manner, views from members of the Focus Group Discussions echoed this perception. According to them, people in the community had seen that the program was good because it has been introduced to them by the government and for that matter, getting the majority of the people aware of it was the only remaining thing and once this was done, many people found it comfortable to join. One member explained that: 'As government introduced the program, we were ready to be part of it but people needed to be given more information about it. People were informed and became aware of the program. Joining it was not a problem anymore.'

The second most important socio-cultural factor that participants in the examined joint funded development program found crucial to join the program was the factor of beliefs. This finding is similar with the views of Apsalone and Sumilo (2015) who through his study found that having belief among the intended program participants increases their participation in the program because this leads to building of trust among the participants.

This therefore implies that in the context of the examined program, having belief among the participants was crucial in encouraging many people to participate in the program. Hence, thirty-four-point eight percent $(34.8 \%)$ of the participants revealed that this was among the factors that played a crucial role in influencing people to join the program. According to them, people believe if they are made aware about the program. One of the participants in favour of this view narrated that:

'It was very possible that even after I had been informed about the program and am aware of it, I still could have chosen to decline joining the program if I did not believe that this program was genuine. Besides being made aware, I need to work on my consciousness about the program'

Indeed, as captured in the quote from one of the interviewed program participants, a similar feeling was expressed by members in the Focus Group Discussions and the Program Director as key informant.

According to the members from the Focus Group Discussions, on account of what had transpired the in past with some of the programs that were introduced in the community, people needed to believe that the program was genuine. As such belief among people was another very important factor in influencing people to join a program. A member from the Focus Group Discussion commented that:

'We have had bad experience with some of the programs that were introduced to us in this community. That is why people at the start were sceptical about the program until they were made to believe and convinced that the program was genuine.'

The Program Director as a key informant echoed these views by explaining that:

'Our mission was to begin by building people's confidence in the program so that they believe in it. We have done and continue to do this by being transparent in every step of the program. We provide participants with all the needed information and as we move into the second phase of the program, we want to build on that so that people continue to believe in the program which will further enhance their participation." 
Lastly, findings on socio-cultural determinants, revealed that attitude was another important determining factor in influencing people's participation in the program. This finding concurs with the findings of Said (2016) who also found that attitude was influential in encouraging people to participate in programs.

According to the participants, positive attitude of the individual towards the program was necessary considering the program benefits will be realized in the long run. From the findings, eighteen-point eight percent $(18.8 \%)$ of the interviewed attested to this view. Figure 5 presents the findings of this analysis.

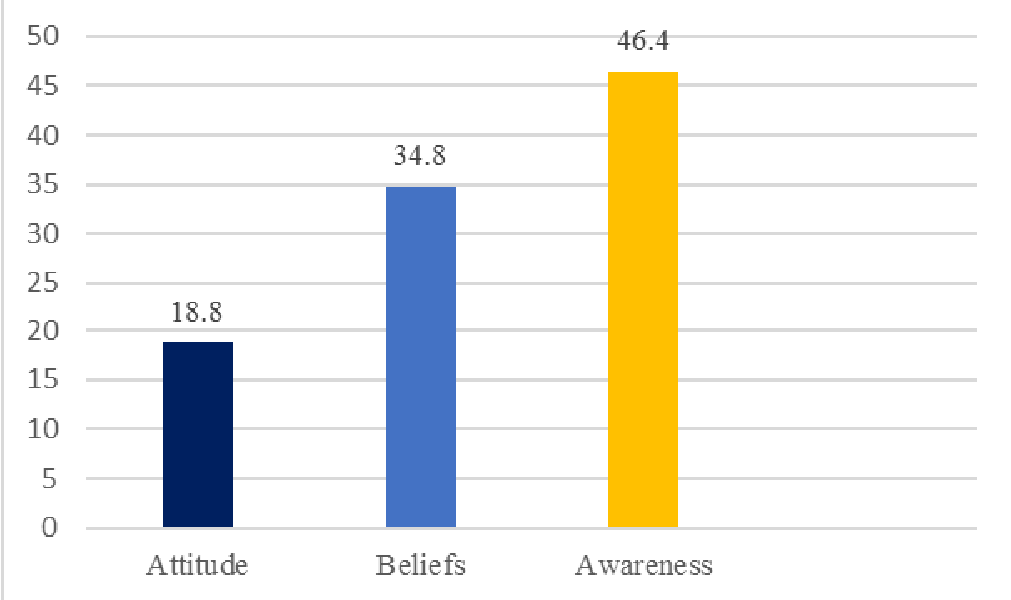

Figure 5: Socio-cultural Determinants in Joint Funded Development Programs

Source: Field Survey, 2020

By and large, the findings on the socio-cultural determinants for effective community participation in joint funded development programs as per the current study revealed that in programs of this nature, factors relating to awareness, beliefs and attitude are very crucial in influencing people's participation.

Hence, by drawing from Apsalone and Sumilo (2015), who stressed that a combination of social and cultural factors can determine the extent of people's participation in a development initiative such as a program or project, the findings of this study on joint funded development program confirm to this perception.

Similarly, the findings further confirm that even in a joint funded development program, the influence of socio-cultural determinants on effective participation of people in programs of this nature may require a combination of socio-cultural factors and not just a single factor.

\subsection{RESULTS AND DISCUSSIONS BASED ON THE COMPARATIVE CASE ANALYSIS}

The socio-cultural determinants for effective community participation in development programs, based on the four examined development programs, this study found that a great number of factors were cited by respondents from the four examined programs as being influential in their involvement in the programs. Again, it is noted from the findings that, much as several factors were pointed out, their degree of influence varied between programs and in some instances, some factors were not found influential in other program categories.

Nevertheless, the cited socio-cultural factors include attitude, values, skills/capacity, beliefs, awareness and others such as interest. However, across all the four examined development programs, the findings showed that, socio- cultural factors that include attitude, beliefs and awareness were most emphasized by the study respondents as factors that mostly influenced them to participate in the different examined development programs.

Despite being the most influencing factors, the study further found that the degree of influence for each of the three factors in the four programs did vary. For instance, the factor of attitude was cited by twenty eight point four percent $(28.4 \%)$ in the locally fully funded development program which made it the most influencing factor in this particular program while in the government fully funded program it was cited by fourteen point three percent $(14.3 \%)$ of the respondents, in the donor fully funded program it was cited by sixty point nine percent $(60.9 \%)$ of the respondents and in the joint funded program it was cited by eighteen point eight percent $(18.8 \%)$ of the respondents. To this effect, the factor of attitude was found to be more influencing in the locally fully funded development program and the donor fully funded development program.

In the case of belief factor, this was cited by twenty-seven-point three percent $(27.3 \%)$ of the respondents in the locally fully funded program, fourteen-point three percent $(14.3 \%)$ in the government fully funded program, two-point three percent $(2.3 \%)$ in the donor fully funded program and thirty-four-point eight percent $(34.8 \%)$ in the joint funded development program. This implies that, belief factor was found to be more influencing in the locally fully funded development program and in the joint funded development program.

Concerning awareness factor, this was cited by twenty seven percent $(27 \%)$ in the locally fully funded development program, sixty-four-point three percent $(64.3 \%)$ in the government fully funded program, thirty- 
two-point two percent $(32.2 \%)$ in the donor fully funded program and forty-six-point four percent $(46.4 \%)$ in the joint funded development program.

On account of the fact that the three socio-cultural factors were found to be very influential across the four examined development programs, the study confirms that, the factor of awareness whose average influence was forty-two-point five percent $(42.5 \%)$ stood out as the most influencing socio-cultural determinant for the effective community participation in development programs (see Table 1).

This therefore implies that from the socio-cultural perspective, the factor of awareness must always be addressed regardless of the nature of the program for effective community participation.

Table 1: Average score for Key Cited Socio- Cultural Determinants

\begin{tabular}{|c|c|c|c|c|c|c|}
\hline \multirow{2}{*}{$\begin{array}{l}\text { Socio-Cultural } \\
\text { Determinant }\end{array}$} & \multicolumn{4}{|c|}{ Percentage $(\%)$} & \multirow{2}{*}{$\begin{array}{l}\text { Average } \\
\text { Percentage } \\
(\%)\end{array}$} & \multirow[t]{2}{*}{ Rungs } \\
\hline & $\begin{array}{l}\text { Locally } \\
\text { Funded } \\
\text { Program } \\
\end{array}$ & $\begin{array}{l}\text { Government } \\
\text { Funded Program }\end{array}$ & $\begin{array}{l}\text { Donor } \\
\text { Funded } \\
\text { Program } \\
\end{array}$ & $\begin{array}{l}\text { Joint } \\
\text { Funded } \\
\text { Program }\end{array}$ & & \\
\hline Awareness & 27.0 & 64.3 & 32.2 & 46.4 & 42.5 & $1^{\mathrm{st}}$ \\
\hline Attitude & 28.4 & 14.3 & 60.9 & 18.8 & 30.6 & $2^{\text {nd }}$ \\
\hline Beliefs & 27.3 & 14.3 & 2.3 & 34.8 & 19.7 & $3^{\text {rd }}$ \\
\hline
\end{tabular}

Source: Field Survey, 2020

By and large, the findings on socio-cultural determinants for effective community participation as revealed in the four examined development programs confirm views of authors such as Apsalone and Sumilo (2015) on the influence of socio-cultural determinants to effective community participation. On the other hand, study findings also revealed that effective community participation in a single development program could be influenced by multiple socio-cultural determinants but the difference will be in the intensity of influence posed by each determinant. For some determinants the intensity will be high while for others it will be very limited.

Based on these findings and regardless of the extent of intensity posed by each socio-cultural factor, this study advocates for the view that since each factor has its own degree of influence, then it will be important to ensure that all socio-cultural factors anticipated to influence the extent of participation in a particular development program be given the attention they deserve.

This is to avoid the risk of having some people left out from participating in the program simply because some factors that seemed meaningless were ignored. By doing so, it will promote meaningful participation in the program as advocated for by authors such as Shutte (2016), Wasilwa (2015), Beck and Crawley (2002) as well as Arnstein (1969).

\section{CONCLUSION, STUDY IMPLICATIONS, CONTRIBUTIONS AND FUTURE RESEARCH DIRECTION}

In this paper, emphasis was put on exploring from an empirical perspective, what could be the socio-cultural determinants for promoting effective community participation in development programs so as to enhance program sustainability in the context of Tanzania. We therefore conclude by briefly foregrounding some of the study's implications for practice, and some of the directions for future research that emerged from the study.

\subsection{STUDY IMPLICATIONS FOR PRACTICE}

Based on the study findings, the study revealed that from the socio-cultural perspective, although there could be several socio-cultural determinants for effective community participation in development programs in Tanzania, more attention should be paid on factors such as awareness, attitude and belief. These three factors were found to be the most pressing factors across all the four examined program categories.

\subsection{STUDY CONTRIBUTIONS}

Accordingly, the first major practical contribution of this research is that it provides much needed empirical knowledge and information on the key socio-cultural determinants for effective community participation in development programs in Tanzania. Precisely those key determinants include awareness, attitude and beliefs

Secondly, the study has revealed that depending on the program funding mechanism i.e., locally fully funded, government fully funded, donor fully funded or Joint fully funded program, social-cultural determinants may vary from one program type to another in some instances. To this effect, it should never be assumed that one socio-cultural factor can have the same impact across different program categories as observed from the findings of the study.

\subsection{FUTURE RESEARCH DIRECTION(S)}

This study focused on examining the what question with regard to the socio-cultural determinants needed to ensure effective community participation in development programs. A further research opportunity could aim at 
exploring the how question in order to determine how effectively these socio-cultural determinants could be implemented so as to enhance effective community participation in development programs.

\subsection{REFERENCES}

Agosti, M.T., Andersson, I., Bringsén, Å. et al (2019): "The importance of awareness, support and inner strength to balance everyday life" - a qualitative study about women's experiences of a workplace health promotion program in human service organizations in Sweden. BMC Women's Health $19,7$. https://doi.org/10.1186/s12905-018-0704-Z

Akumu. M and Onono. P (2017): Community Participation and Sustainability of the Kenya Comprehensive School Health Program in Kajiado County, Kenya, Unpublished

Apsalone, M., \& Šumilo, E. (2015). Socio-Cultural Factors and International Competitiveness. Business, Management and Education, 13(2), 276-291. DOI: 10.3846/bme.2015.302

Arnstein. S (1969): The Ladder of Citizen Participation. The Journal of the American Planning Association, 35 , (4): $216-224$

Bamber. J, Owens. S, Schonfeld. H, Ghate. D and Fulerton. D (2010): Effective Community Development Programs: A Review of International Evidence Base. Published by the Centre for Effective Services, Dublin, Iceland.

Beck. A \& Crawley. C (2002): Education, ownership and solutions: the role of community involvement in achieving grass roots sustainability, Regional Institute Online Publishing, North South Wales, Australia.

Kumar. R (2011): Research Methodology: A Step-by-Step guide for beginners, $3^{\text {rd }}$ Edition, SAGE Publishers, New Delhi, India.

Lilja, E (2017): The Challenges of partnership in the light of citizens' participation, Faculty of Culture and Society, Malmo`University

Mohammad, N (2010): People Participation in Development Projects at Grass-Root Level. A Case Study of Alampur and Jagannathpur Union, Parishad. Unpublished

Nkonjera. A. (2008): Community participation in water development projects in Mbeya District, Tanzania. Morogoro. Unpublished

Odoyo. C (2013): Factors affecting implementation of community projects: Case of Kimira-Oluch smallholder farm improvement project in Homa Bay County, Kenya. Universal Journal of Management,1(2),111 - 118

Said, S.A. (2016). Community attitude towards the relevance of community education programs in Tanzania: The case of Wete district. Dodoma: Master Thesis, The University of Dodoma.

Schutte, D. W. (2000): Community Development and Community Participation: A Conceptual Revisit. Entwicklungsethnologie, $\quad 9(1), \quad$ 12-26. $\quad$ Retrieved from https://www.academia.edu/28898875/CommunityDevelopment_and_Community_Participation_a_Concept ual_Revisit_De_Wet_Schutte_1

Sebastian. I.C, Eduard.G.C. Cristian, E.L and Luliana.L (2018): Community Based Programs Sustainability. A Multidimensional Analysis of Sustainability Factors

Sibanda, D. (2011). The role of community participation in development initiatives: the case of the Danga ecological sanitation project in the zvishavane district, Zimbabwe. Unpublished.

UNDP (2013): Human Development Report. The Rise of the South: Human Progress in a Diverse World, New York

Wasilwa. C (2015): Effects of Community Participation on Sustainability of Community Based Development Projects in Kenya, Unpublished.

Yin, R (2003): Applications of Case Study Research (2nd ed). Thousand Oaks: Sage Publications, London. 